BIOMEDICA

Vol. 3, No. 3 - 1983

COMUNICACIONES BREVES

\title{
INFRECUENCIA DE LA TRICOMONIASIS COMO CAUSA DE URETRITIS MASCULINA
}

\author{
ESTUDIO POR CULTIVO
}

FEDERICO DIAZ G., * ANGELA PEREZ DE E., * MARIA I. VELEZ G., ** OLGA L. JIMENEZ M. **

\begin{abstract}
En sólo 3 de 92 hombres (3,3\%) con uretritis no gonocócica (UNG) se halló la Trichomonas vaginalis por cultivo; en dos de ellos el examen directo había revelado el parásito; estos resultados confirman la baja frecuencia, previamente informada, de este protozoo en casos de UNG y permiten proponer que el cultivo para Trichomonas no está justificado en hombres con tal cuadro clínico.
\end{abstract}

\section{INTRODUCCION}

Experiencias prospectivas y retrospectivas previamente publicadas por uno de nosotros $(1,2)$ demostraron una baja frecuencia de tricomoniasis como causa de uretritis masculina $(3,1 \%$ y $0,8 \%$ respectivamente); en ambas series la búsqueda del parásito se hizo solo por examen en frasco. Se planteó entonces la posibilidad de que el uso del cultivo pudiera incrementar esa frecuencia; el presente es el informe de los resultados obtenidos con tal procedimiento en 92 individuos con uretritis no gonocócica (UNG).

\section{MATERIALES Y METODOS}

El estudio se llevó a cabo en un laboratorio clínico que atiende personas remitidas en ejercicio de la práctica privada y también presta servicio a los beneficiarios de varias instituciones oficiales.

Se estudiaron 92 hombres, entre el 12 de agosto y el 30 de noviembre de 1983, que cumplían los criterios necesarios para hacer el diagnóstico de UNG $(1,2)$. Se les hizo búsqueda de Trichomonas vaginalis en el sedimento de la primera porción de orina matinal, tanto por examen en fresco entre lámina y laminilla como por cultivo en un tubo de medio bifásico (3) empleando la modificación introducida por Restrepo (4); el cultivo se incubó a $37^{\circ} \mathrm{C}$ y se hizo lectura a las 24 y 48 horas obteniendo para ello una gota de la parte más profunda de la fase líquida.

\section{RESULTADOS}

En dos pacientes $(2,2 \%)$ el examen directo fue positivo para Trichomonas vaginalis; en ellos, y en uno adicional, hubo crecimiento del parásito en el cultivo $(3,3 \%)$.

Los tres individuos aquejaban disuria y dos, prurito uretral; solo uno tenía secreción uretral, de modalidad purulenta y de intensidad III (1); la evolución de la sintomatología había sido de 3 y 4 días en dos pacientes y de 8 meses en el tercero; éste había recibido antibioterapia con 5 drogas diferentes; los períodos de incubación fueron de 3, 4 y 17 días.

* Profesores, Departamento de Microbiología y Parasitología, Facultad de Medicina, Universidad de Antioquia.

** Bacteriólogas, Laboratorio Clínico, carrera 45 No. 53-50, Medellín. 


\section{DISCUSION}

Este estudio confirma la baja frecuencia con que se halla la $\mathrm{T}$. vaginalis en hombres con uretritis no gonocócica pertenecientes al estrato socio-económico que acude a un laboratorio como el descrito; demuestra también que, en tales circunstancias, no está justificado el cultivo para Trichomonas; sin embargo es concebible que en otros estratos la situación sea diferente y amerite ser estudiada tanto por examen directo como por cultivo. Para tal eventualidad es pertinente anotar que el cultivo para Trichomonas es fácil de realizar y requiere sólo materiales corrientemente disponibles $(3,4)$; por lo que respecta a su confiabilidad, Restrepo (4) llevó a cabo un estudio de flujos vaginales recurriendo tanto al directo como al cultivo y halló que de 157 casos positivos, por uno u otro método, había $141(89,8 \%)$ que lo eran en el cultivo y que en 28 de ellos el cultivo había sido la única forma de comprobar la positividad.

En general otros autores $(5,6)$ han hallado cifras comparables a las nuestras cuando buscan $T$. vaginalis en hombres con UNG; Kuberski (5) detectó el parásito en el 1,7\% de 179 hombres con tal síndrome; Holmes (6) y Wisdom (citado en 5) lo hallaron con frecuencias que fluctuaban desde menos del $1,0 \%$ hasta el $5,3 \%$; la excepción a este patrón de baja frecuencia está en el trabajo de Whittington (citado en 5) que halló $T$. vaginalis en el 15,3\% de hombres con UNG; Kuberski (4) planteó la posibilidad de que el parásito pueda ser más importante en pacientes que, además de UNG, tienen prostatitis; en efecto, en 4 de 11 pacientes con tal diagnóstico se halló evidencia serológica de infección reciente por T. vaginalis y en dos de los cuatro los cultivos para el parásito fueron positivos.

Una explicación plausible de la baja frecuencia de tricomoniasis en este grupo de hombres y en los anteriormente estudiados $(1,2)$ es que la $T$. vaginalis también es infrecuente en la población femenina que acude al mismo laboratorio; en efecto, datos no publicados demostraron Trichomonas sólo en $151(4,1 \%)$ de 3.728 mujeres estudiadas entre 1981 y 1983 para definir la etiología del flujo vaginal.

\section{SUMMARY}

Only three of 92 men with ningonococcal uretrhritis were found to be positive when urine sediment was cultured for Trichomonas vaginalis; two of them had been positive on direct examination as well. These results confirm the low frequency of Trichomonas male urethritis and allow to rule out the usefulness of the culture for Trichomonas en such patients.

\section{AGRADECIMIENTO}

A los médicos que nos refirieron sus pacientes para estudios microbiológicos.

\section{BIBLIOGRAFIA}

1. Díaz, F. Uretritis masculina gonocócica y no gonocócica. Papel del laboratorio clínico en su diagnóstico microbiológico. Biomédica, 1982, 2 (4) : 172.

2. Díaz, F. Uretritis masculina. Estudio prospectivo de 254 casos. Biomédica, en prensa.

3. Kupferberg, AB., Johnson, G., Sprince, H. Nutritional requirementes of Trichomonas vaginalis. Proc Soc Exp Biol Med, 1948, 67 (3) 304.

4. Restrepo, M. Estudio de 1.200 flujos vaginales. Ant Méd, 1964, (1): 4.

5. Kuberski, T. Trichomonas vaginalis associated with nongonococcal urethritis and prostatitis. Sex Transm Dis, 1980, 7 (3): 135.

6. Holmes, KK., Handsfield, HH., Wang, SP., et al. Etiology of nongonoccal urethritis. N Engl J Méd, 1975, 292 (23): 1199. 